\title{
Invasive lionfish increase activity and foraging movements at greater local densities
}

\author{
Cassandra E. Benkwitt* \\ Department of Integrative Biology, Oregon State University, Corvallis, OR 97331, USA
}

\begin{abstract}
Density-dependent changes in predator foraging behavior due to intraspecific competition for food can have important implications for population dynamics of both the predator and its prey. The Indo-Pacific red lionfish Pterois volitans is an invasive predatory reef fish that has reached high population densities and can cause large reductions in small native fishes. To determine whether lionfish behavior or movement varies with local lionfish and/or prey densities, I conducted observations of lionfish on 16 coral patch reefs in The Bahamas. Lionfish foraging activity and movement varied significantly with lionfish density. At higher densities, lionfish exhibited greater activity levels, time away from shelter, and more short-term foraging movements between coral patch reefs and surrounding seagrass habitats. However, these changes were not uniform throughout the day, with differences in activity occurring only at dusk and differences in movement occurring at both dawn and dusk, but not midday. Although some lionfish foraging behaviors varied with prey density, overall lionfish density was more strongly related to differences in lionfish activity patterns. These temporal and spatial changes in lionfish foraging behaviors are consistent with the predicted effects of intraspecific competition and may have important consequences for lionfish removal efforts and native prey populations. Specifically, in areas with higher lionfish densities, prey fishes that are more active at dusk and/or inhabit seagrass beds near coral patch reefs may be more vulnerable to lionfish predation. By culling lionfish, managers may reduce the local foraging movements of lionfish and thus help maintain native fish communities in multiple habitats.
\end{abstract}

KEY WORDS: Behavior - Coral-reef fishes - Density dependence - Intraspecific competition · Movement $\cdot$ Non-native $\cdot$ Predator-prey interaction $\cdot$ Pterois volitans

\section{INTRODUCTION}

Local population density can strongly influence individual behavior and demographic rates through a variety of mechanisms. In some species there are benefits to living in groups, including increased access to mates, increased hunting efficiency, and reduced risk of predation (Packer \& Ruttan 1988, Courchamp et al. 1999, Krause \& Ruxton 2002, Gascoigne \& Lipcius 2004). However, at high densities, intraspecific competition for food and shelter often causes reductions in individual growth and survival due to increased interference and/or exploitation of resources (Jones 1991, Keddy 2001, Krause \& Ruxton 2002, For-

\footnotetext{
${ }^{*}$ Corresponding author: benkwitc@science.oregonstate.edu
}

rester 2015). Density-dependent behavioral and demographic changes are not only important to the population dynamics and regulation of a single species (Murdoch 1994, Hixon et al. 2002), but can also influence community-level dynamics and ecosystem processes (Micheli 1997, Clark et al. 2000).

If there is increased competition for food at higher conspecific densities, then predators may alter their foraging behavior in several ways, with subsequent consequences for prey populations. For example, if it takes longer to find and consume prey due to increased resource depletion or interference while foraging at higher densities, some individuals may increase the amount of time spent foraging (Clark \& Mangel 1986,

() The author 2016. Open Access under Creative Commons by Attribution Licence. Use, distribution and reproduction are unrestricted. Authors and original publication must be credited. 
Shaw et al. 1995, Anholt \& Werner 1995, Grand \& Dill 1999, Bohlin \& Johnsson 2004, White \& Warner 2007), which may also be accompanied by an increase in conspecific aggressive encounters (Pintor et al. 2009, Kaspersson et al. 2010). Species that differentially forage over a diel cycle can expand their foraging time by hunting for longer during their typical hunting hours and/or by hunting at more periods of the day (Lawton 1987, Kronfeld-Schor \& Dayan 2003, Wasserberg et al. 2006). Hunting at more periods of the day could in turn cause prey species with various diurnal patterns to be differentially susceptible to predation. In addition, predators at higher densities may expand their foraging range, which could enable them to exploit resources that have not yet been depleted and/or escape aggressive interactions in the areas with high densities of conspecifics (Micheli 1997, Forrester et al. 2006, Breed et al. 2013). If predators forage over broader distances, then prey species that inhabit the newly exploited habitats may be consumed.

Changes in foraging behavior as a result of increased local density may be particularly important to the population dynamics of both introduced predators and their native prey. Invasive species often reach higher abundances and individual body sizes in their invaded compared with their native ranges (Sakai et al. 2001, Grosholz \& Ruiz 2003), and thus are likely to be strongly affected by intraspecific interactions. Furthermore, many invasive species are both competitively dominant and more abundant than ecologically similar native species in their new locations (Parker et al. 1999, Mack et al. 2000, Mooney \& Cleland 2001, Sakai et al. 2001), suggesting that intraspecific rather than interspecific competition will have a larger influence on invasive species. Because invasive predators often cause larger reductions in native prey populations than do native predators (Salo et al. 2007), it is crucial to understand their foraging behavior at different densities and how this behavior in turn influences prey populations.

The Indo-Pacific red lionfish Pterois volitans is an invasive predatory reef fish that has reached extremely high abundances in parts of its invaded range (Côté et al. 2013, Albins \& Hixon 2013). Since they were first sighted off the coast of Florida in the mid-1980s, lionfish have spread throughout the Caribbean, the Gulf of Mexico, and along the east coast of the Americas (Schofield 2010). Lionfish densities on reefs in their invaded range can be several orders of magnitude higher than in their native range (Green \& Côté 2009, Darling et al. 2011, Kulbicki et al. 2012, McTee \& Grubich 2014). At the same time, there is wide variation in lionfish densities within their invaded range, owing in part to differences in the length of time since establishment (Ruttenberg et al. 2012, Dahl \& Patterson 2014), removal efforts (Frazer et al. 2012, de León et al. 2013), and abiotic site characteristics including depth and exposure to strong currents and wave surge (Whitfield et al. 2007, Anton et al. 2014). In contrast, invasive lionfish populations are likely unaffected by potential predators (Hackerott et al. 2013, Valdivia et al. 2014, but see Mumby et al. 2011) or interspecific competitors (Albins 2013), especially given that native predators are severely depleted throughout much of the Caribbean (Paddack et al. 2009, Stallings 2009).

Despite differences in lionfish densities both between and within their native and invaded ranges, how local lionfish density influences their hunting behavior has not yet been examined. Both native and invasive lionfish are primarily crepuscular hunters, with peaks in activity and stomach fullness occurring at dawn or at both dawn and dusk (Fishelson 1975, Morris \& Akins 2009, Green et al. 2011, Cure et al. 2012, McTee \& Grubich 2014). Invasive lionfish are extremely efficient predators, as they have high prey consumption rates (Albins \& Hixon 2008, Côté \& Maljkovic 2010) and cause large reductions in the abundance, biomass, and richness of native coral reef fishes (Albins \& Hixon 2008, Albins 2013, 2015, Green et al. 2014, Benkwitt 2015). There is evidence that invasive lionfish experience intraspecific competition for food, as lionfish at higher densities on small patch reefs exhibit slower growth (Benkwitt 2013) and have diminishing per-capita effects on prey abundance and biomass (Benkwitt 2015). Given the effect of lionfish density on their individual growth rates, it seems likely that their foraging patterns also change at different local densities.

I conducted observations of lionfish to test the hypothesis that lionfish behavior changes at different lionfish and prey fish densities due to intraspecific competition for food. Specifically, I predicted that if there is intraspecific competition for food, then at higher lionfish densities and/or lower prey fish densities, lionfish will alter their foraging activity by (1) increasing the amount of time spent active and hunting at crepuscular periods and/or (2) increasing the number of periods per day during which they are active and hunting. In addition, I expected that lionfish would change the locations at which they hunt such that they would (3) spend less time sheltering within the reef and (4) increase the distances over which they travel while hunting at higher densities. 


\section{MATERIALS AND METHODS}

\section{Study sites}

This study was conducted between June and August 2012 on coral patch reefs in Rock Sound near Cape Eleuthera, The Bahamas $\left(24^{\circ} 50^{\prime} 2.65^{\prime \prime} \mathrm{N}, 76^{\circ}\right.$ $\left.16^{\prime} 6.78^{\prime \prime} \mathrm{W}\right)$. Lionfish first arrived at the study site in 2005 and there has been virtually no removal effort in the area, with the exception of isolated lionfish removals for field experiments (Green et al. 2014, Côté et al. 2014). I selected 16 reefs on which lionfish had not been previously manipulated and that were at least $300 \mathrm{~m}$ from any reef on which lionfish removals had occurred, which is greater than the maximum distance travelled by the majority of lionfish in the study area (Tamburello \& Côté 2015). Reefs were selected to encompass a range of natural lionfish densities (1-16 lionfish reef ${ }^{-1}, 0.04-1.01$ lionfish $\mathrm{m}^{-2}$ ) and reef sizes (7.88-32.99 $\mathrm{m}^{2}$ surface area), and there was no significant correlation between lionfish density and reef size (correlation $=-0.11, t=$ 0.56, $\mathrm{p}=0.58$ ). Reefs were similar to each other in terms of rugosity, benthic community (algae-covered dead coral, live coral, and sponges), and surrounding habitat (sand and seagrass). Lionfish size on the reefs ranged from 6 to $30 \mathrm{~cm}$ total length (TL; mean = $18.2 \mathrm{~cm})$, with the majority of lionfish (>90\%) between 15 and $25 \mathrm{~cm}$ TL.

\section{Lionfish behavior and movement}

A pair of divers (observers) visited each reef at 3 times of day: within sunrise $+2 \mathrm{~h}$ ('dawn'), $>3 \mathrm{~h}$ after sunrise and $>3 \mathrm{~h}$ before sunset ('midday'), and within sunset $-2 \mathrm{~h}$ ('dusk'). During the study, sunrise varied between approximately 06:30 and 06:50 h and sunset varied between 19:30 and 20:00 h. Upon arriving at a reef, observers counted the number of lionfish present by conducting lionfish-focused searches, which involved first slowly circling reefs and then swimming over reefs until all areas had been covered. Divers paid particular attention to crevices and overhangs where lionfish are commonly found, and because of the small size of the reefs it was possible to thoroughly search the entire reef area. For each lionfish, observers recorded the size (TL visually estimated to the nearest $\mathrm{cm}$ ), behavior, and location the moment it was sighted. Behaviors were categorized as resting (sitting on the substrate, not moving), hovering (in the water column oriented parallel to the bottom, but not moving), swimming (actively mov- ing), or hunting (oriented head down with pectoral fins flared), with the latter 3 categories broadly grouped together as 'active' for some analyses. Similar classifications have been used in previous studies of lionfish behavior (Côté \& Maljkovic 2010, Green et al. 2011, Cure et al. 2012). Location was categorized as the microhabitat on which lionfish were observed (e.g. under a ledge, on top of the reef, in the surrounding seagrass) and later divided into 2 major categories: sheltering (hidden under structure) or exposed (on top of reef or in surrounding area).

Then, 10-min focal observations were conducted on 2 lionfish selected using randomly generated numbers, or a single lionfish when there was only one individual present per reef. During focal observations, a trained observer recorded the behavior of lionfish at $30 \mathrm{~s}$ intervals for $10 \mathrm{~min}$ using the same categories as above. Simultaneously, a second observer videorecorded the focal lionfish to enable later analyses and confirmation of behaviors and allow divers to keep track of lionfish movement (see next paragraph). The observers also noted any strikes at prey, successful kills, and obviously aggressive interactions (chases, posturing) between lionfish or between lionfish and other species. However, there were very few observed strikes and aggressive interactions by focal lionfish, so those data were not analyzed. The observers maintained a distance of approximately $3 \mathrm{~m}$ from focal lionfish, a distance at which divers have no apparent influence on lionfish behavior (Côté \& Maljkovic 2010, Green et al. 2011, Cure et al. 2012).

Throughout the entire visit to each reef, divers noted the time when any lionfish departed from or arrived at the reef and its behavior. A lionfish was defined as departing from the reef if it traveled at least $10 \mathrm{~m}$ from the reef. A lionfish was considered arriving at a reef if it swam in from the surrounding areas and had not been previously observed at that reef during that observation period. In only 3 instances were divers unsure whether an arriving lionfish was a new individual, as a lionfish was seen departing from the reef and traveled out of sight, and soon after another lionfish of the same size and coloration from the same direction returned. In these cases, it was assumed that these were the same lionfish rather than new individuals. Because the reefs were relatively small and divers had an unobstructed view of the surrounding area, the observers were reasonably confident that they counted all arrivals and departures of lionfish. However, because observers were most likely to miss arrivals and departures on reefs with the highest lionfish densities, if 
anything these results likely underestimate the effect of lionfish density on movement.

At the conclusion of the focal observations, the divers re-counted the number of lionfish present while conducting a survey of resident native fishes. Divers recorded the abundance and body size (TL) of all fish 1-15 cm TL, native mesopredators that are ecologically similar to lionfish (e.g. graysby grouper Cephalopholis cruentata), and top predators (e.g. Nassau grouper Epinephelus striatus) on and within $1 \mathrm{~m}$ of the reef. Surveys were conducted by slowly swimming in concentric circles gradually decreasing in size from the reef edge to the center of the reef until the entire reef area was surveyed. By slowly sweeping one hand just above the substrate, divers counted cryptic bottom-dwelling species such as gobies and blennies. Dive lights were used to search for cryptic species in crevices and under ledges.

\section{Statistical analyses}

Because multiple observations were conducted on the same reefs and there was evidence of heterogeneity in residuals based on reef, I conducted a series of generalized linear mixed effects models (GLMMs) fit using Gauss-Hermite quadrature with reef as a random effect (Zuur et al. 2009, Bolker et al. 2009). Fixed effects included lionfish density, prey fish density, and time of day. Because there were large fluxes in lionfish density on the reefs at dawn and dusk due to lionfish moving to and from the surrounding habitats (see 'Results'), I defined lionfish density as the density of lionfish on each reef at midday, which remained relatively constant during each observation period. This measure of lionfish density was significantly positively correlated with the maximum density of lionfish observed on each reef during each of the 3 observation periods (correlation $=0.83$, $t=13.3, \mathrm{p}<0.001$ ), and thus seemed to be an accurate representation of the relative density of lionfish that inhabited each reef throughout the study. Prey density was defined as the density of prey fishes at the time of each visit and was $\log (x+1)$ transformed. I restricted prey fishes to those $\leq 5 \mathrm{~cm}$ TL, which are small enough to be vulnerable to a range of lionfish sizes and encompass the prey sizes most often consumed by all sizes of lionfish (Morris \& Akins 2009, Muñoz et al. 2011). Prey density did not significantly vary with time of day (likelihood ratio test $\chi^{2}=2.75$, $p=0.25$ ) and there was no significant correlation between lionfish density and prey density (correlation $=-0.11, t=0.97, \mathrm{p}=0.33$ ). Because time of day had the largest influence on lionfish behavior in previous studies (Green et al. 2011, Cure et al. 2012) and to test whether the effect of lionfish or prey fish density on foraging behavior varies at different times of day, I also included interactions between time of day and each of the other explanatory variables as fixed effects. All reefs had similar densities of native mesopredators $\left(0-0.05\right.$ fish $\left.\mathrm{m}^{-2}\right)$ and top predators $\left(0-0.30\right.$ fish $\left.\mathrm{m}^{-2}\right)$, so I did not include these as explanatory variables in the analyses.

Response variables to test my predictions regarding lionfish behavior were based on observations of all lionfish on the reefs and on focal observations of individual lionfish. From all lionfish, the responses were the proportion of lionfish on each reef that were hunting upon arrival at the reef and the proportion of lionfish on each reef that were active upon arrival at the reef. From focal lionfish, the responses were the proportion of time individual focal lionfish spent hunting and the proportion of time individual focal lionfish spent active. Response variables to test predictions regarding lionfish position and movement were based on all lionfish on the reefs: the proportion of lionfish on each reef that were sheltering during initial observations, the proportion of lionfish arriving at each reef throughout observations, and the proportion of lionfish departing from each reef throughout observations. Because all responses were proportions, I modeled the data following binomial distributions with logit links. I conducted likelihood ratio tests (LRTs) to test for overall significance of fixed effects and Wald $Z$-tests to test for significance of single parameters (Zuur et al. 2009). All analyses were conducted in $\mathrm{R}$ version 3.0.2 ( $\mathrm{R}$ Core Team 2013) with the associated package lme4 (Bates et al. 2014).

\section{RESULTS}

\section{Lionfish behavior}

A total of 95 lionfish were observed at dawn, 126 at midday, and 117 at dusk on and around the 16 coral patch reefs. A significantly higher proportion of lionfish hunted at dawn compared with at dusk and midday, and significantly more lionfish also hunted at dusk compared with at midday (all $z \geq 3.63$, all $\mathrm{p}<$ 0.001). This effect of time period on the proportion of lionfish hunting on each reef was not modified by lionfish or prey fish density (Lionfish $\times$ Time, Prey $\times$ Time: LRT $\chi^{2}=4.04,2.31, \mathrm{p}=0.13,0.32$, respectively; see Table S1, Figs. S1 \& S2 in the Supplement at 
www.int-res.com/articles/suppl/m558p255_supp.pdf). However, the proportion of time that individual focal lionfish spent hunting varied with both time of day and prey density (Prey $\times$ Time LRT $\chi^{2}=16.91, \mathrm{p}<$ 0.001; Fig. 1A, see Table S1 in the Supplement). At dawn and dusk, lionfish spent significantly more time hunting at higher prey densities $(z=3.09,3.38$, $\mathrm{p}=0.002,0.0007$, respectively), with the odds of a lionfish hunting increasing by a factor of 2.43 at dawn and 2.58 at dusk for each doubling of prey density $(95 \% \mathrm{CI}=1.60-8.12$ and $1.76-8.28$, respectively). Regardless of prey density, lionfish spent very little
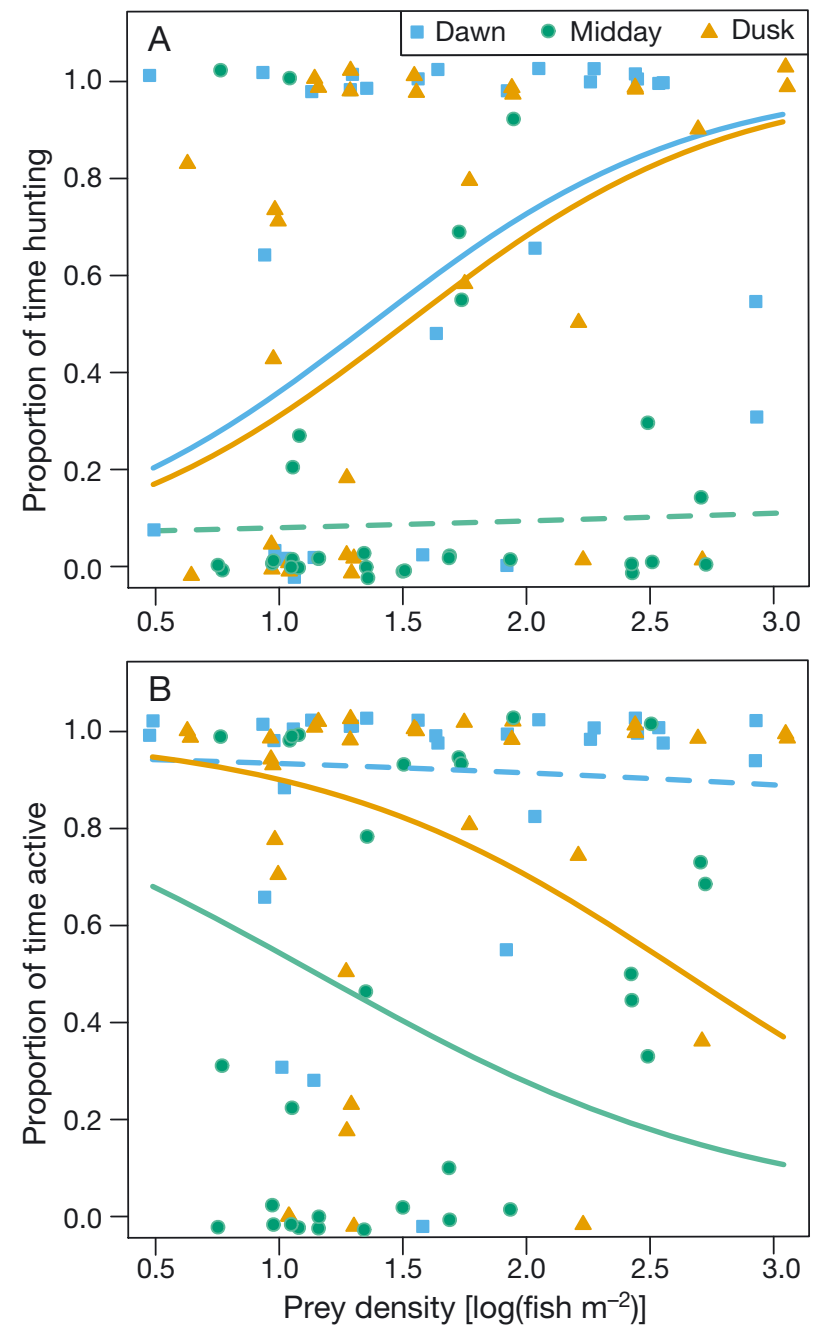

Fig. 1. Pterois volitans. Proportion of time individual focal lionfish spent (A) hunting and (B) active (hovering, swimming, or hunting) as a function of prey fish density at dawn, midday, and dusk. Lines are predicted probabilities based on generalized linear mixed effects models. Dashed lines represent slopes that are not significantly different than zero; solid lines represent slopes that are significantly different than zero $(\mathrm{p}<0.05)$. Points represent individual lionfish and were randomly jittered to reduce overlap time hunting in the middle of the day. There was no significant effect of lionfish density on time spent hunting by focal lionfish at any time of day (all $z \leq$ 1.10, all $\mathrm{p}>0.27$; see Fig. $\mathrm{S} 1$ in the Supplement).

In contrast, the proportion of lionfish active (hovering, swimming, or hunting) varied with both time of day and lionfish density, but not prey density (lionFish $\times$ Time: LRT $\chi^{2}=9.61, p=0.008$; Prey $\times$ Time: LRT $\chi^{2}=0.67, p=0.71$; Fig. 2A, see Table S1, Fig. S2 in the Supplement). Regardless of lionfish density, the majority of lionfish were active at dawn and few were active at midday. At dusk, however, a signifi-
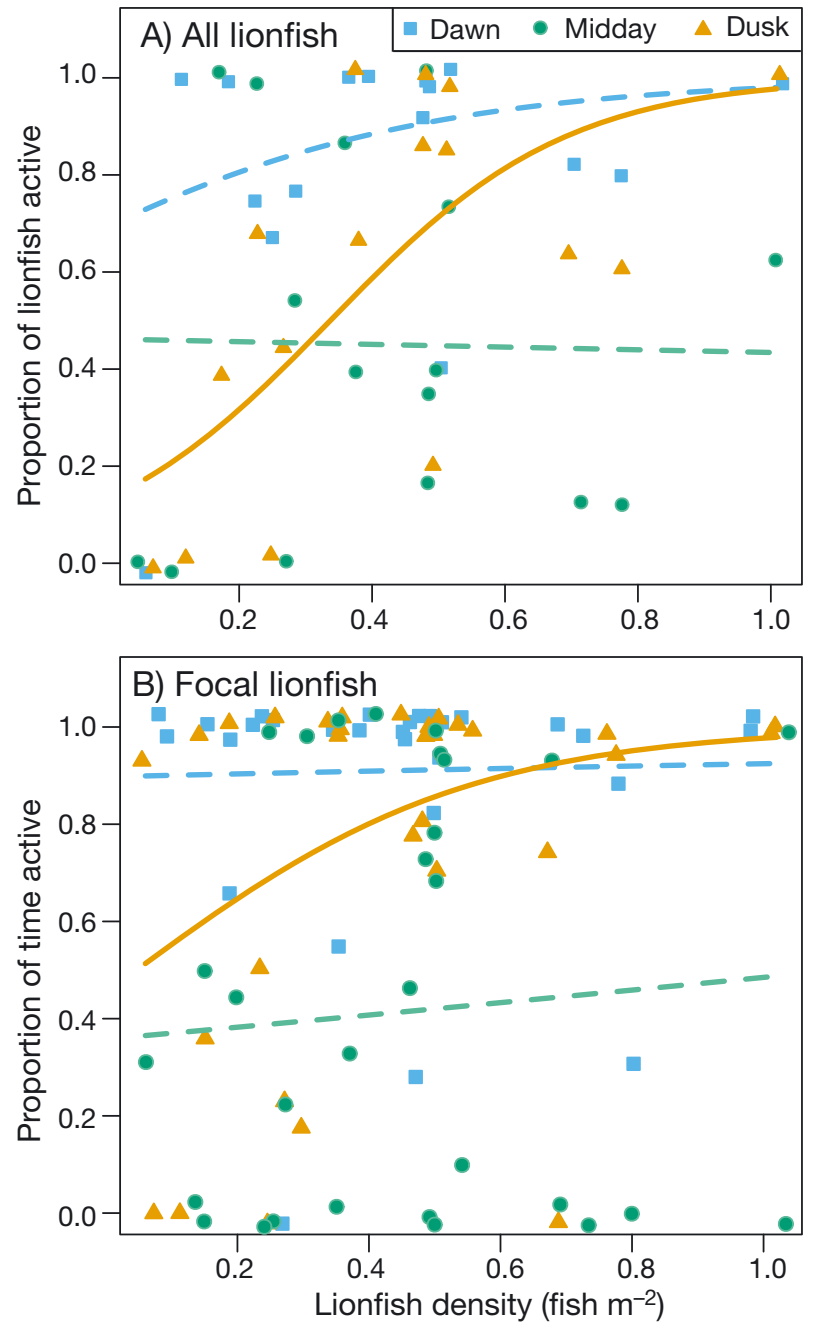

Fig. 2. Pterois volitans. (A) Proportion of lionfish that were active (hovering, swimming, or hunting) upon arrival at the reef and (B) proportion of time individual focal lionfish spent active as a function of lionfish density at dawn, midday, and dusk. Lines are predicted probabilities based on generalized linear mixed effects models. Dashed lines represent slopes that are not significantly different than zero; solid lines represent slopes that are significantly different than zero $(\mathrm{p}<$ 0.05). Points represent reefs (A) and individual lionfish (B) and were randomly jittered to reduce overlap 
cantly higher proportion of lionfish were active at higher lionfish densities, with the odds of a lionfish being active increasing by a factor of 1.78 for each increase in lionfish density by 0.1 fish $\mathrm{m}^{-2}(95 \% \mathrm{CI}=$ $1.21-2.61 ; z=2.93, p=0.003)$. Similar to these reeflevel patterns, individual focal lionfish spent significantly more time active at dusk at higher lionfish densities $(z=2.14, p=0.032,95 \% \mathrm{CI}=1.03-2.07$; Fig. 2B). The amount of time individual lionfish were active at dusk and midday also varied significantly with prey density (Fig. 1B), with the odds of being active decreasing by $37.8 \%$ for each doubling of prey density on a reef at dusk $(95 \% \mathrm{CI}=19.3-73.7 \%, z=$ $2.85, \mathrm{p}=0.004)$ and $42.3 \%$ at midday $(95 \% \mathrm{CI}=$ $19.7-90.5 \%, z=2.22, \mathrm{p}=0.027)$. These activity patterns were primarily driven by hunting and hovering behavior, as no lionfish were observed swimming upon arrival at the reef and focal lionfish spent an average of $1.6 \%$ of their time swimming, compared with $46.3 \%$ spent hunting and $21.1 \%$ spent hovering.

\section{Lionfish movement}

The position of lionfish varied significantly with both lionfish density and time of day, but not with prey density (Lionfish $\times$ Time: LRT $\chi^{2}=14.59, \mathrm{p}<$ 0.001; Prey $\times$ Time: LRT $\chi^{2}=0.88, p=0.64$; Fig. 3A, see Table S1, Fig. S3 in the Supplement). At dusk, for each increase in lionfish density by 0.1 lionfish $\mathrm{m}^{-2}$, the odds of a lionfish sheltering decreased by a factor of $0.58(95 \% \mathrm{CI}=0.39-0.87, z=2.63, \mathrm{p}=0.009)$. The majority of lionfish were exposed at dawn and the majority of lionfish sheltered at midday across all lionfish and prey densities.

Likewise, lionfish exhibited predictable movements between coral patch reefs and surrounding seagrass and sand habitats that varied with lionfish density and time of day, but not with prey density (Lionfish $x$ Time: LRT $\chi^{2} \geq 8.13, \mathrm{p}<0.017$; Prey $\times$ Time: LRT $\chi^{2} \leq$ $4.15, \mathrm{p}>0.13$; Fig. 3B,C, see Table S1, Fig. $\mathrm{S} 3$ in the Supplement). At dawn, a higher proportion of lionfish arrived from the surrounding areas at reefs with greater lionfish densities $(z=2.06, p=0.039$; Fig. 3B). For each increase in lionfish density by 0.1 fish $\mathrm{m}^{-2}$, there was an increase in the odds of a lionfish arriving at the reefs by a factor of $1.42(95 \% \mathrm{CI}=1.02-$ 1.99). At midday, there was very little lionfish movement, regardless of lionfish density. At dusk, a pattern opposite to that at dawn was observed, with a significantly higher proportion of lionfish departing from the reefs at higher lionfish densities $(z=2.96, \mathrm{p}=$ 0.003; Fig. 3C). For each additional 0.1 lionfish $\mathrm{m}^{-2}$ on
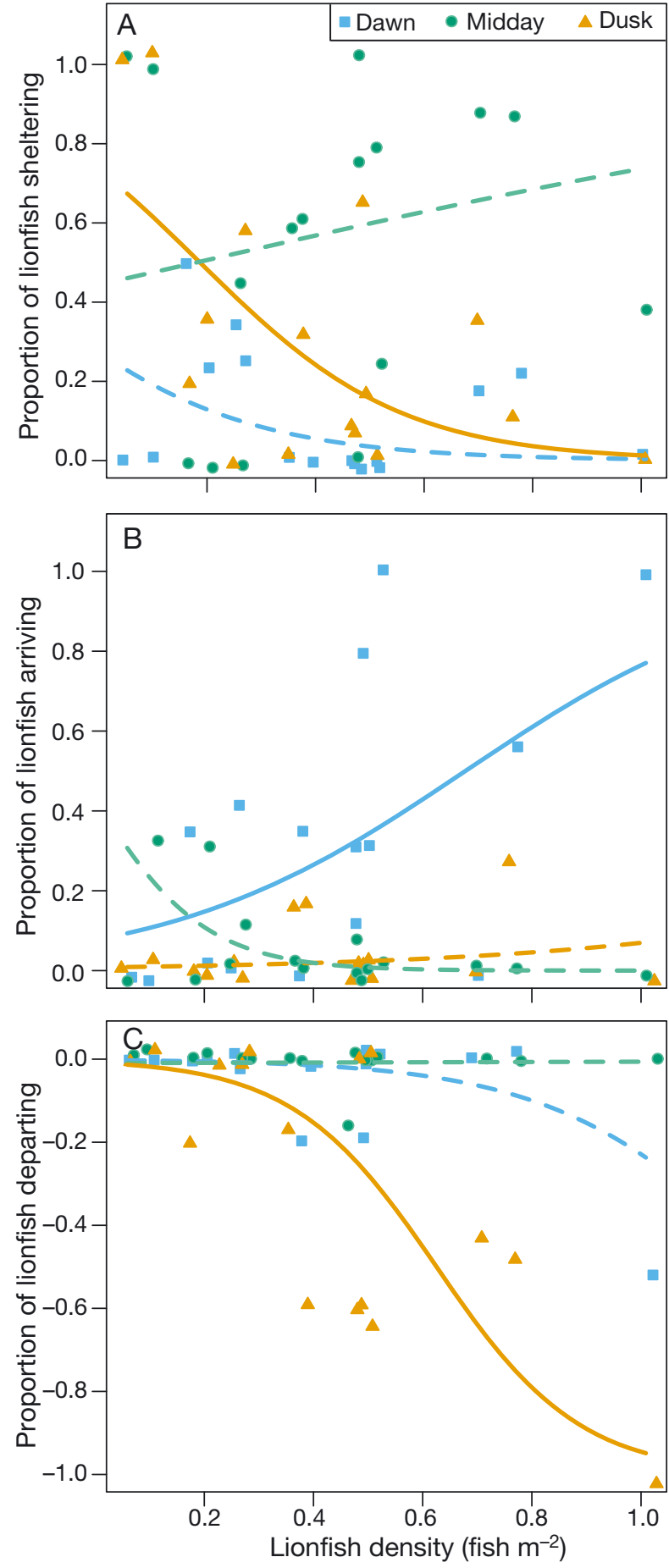

Fig. 3. Pterois volitans. (A) Proportion of lionfish that were sheltering upon arrival at the reef, (B) proportion of new lionfish that arrived at each reef, and (C) proportion of lionfish that departed from each reef as a function of lionfish density at dawn, midday, and dusk. Lines are predicted probabilities based on generalized linear mixed effects models. Dashed lines represent slopes that are not significantly different than zero; solid lines represent slopes that are significantly different than zero $(p<0.05)$. Points represent reefs and were randomly jittered to reduce overlap 
a reef, the odds of a lionfish departing from the reef at dusk increased by a factor of 2.57 (95\% CI = 1.75-4.79). Approximately $50 \%$ of the lionfish that departed from a reef returned to the same reef within the observation period. Larger lionfish exhibited more movements between coral patch reefs and the surrounding habitats, whereas no lionfish less than $15 \mathrm{~cm}$ TL was ever observed arriving at or departing from the reefs (Fig. 4).

\section{DISCUSSION}

There were significant differences in lionfish foraging activity and movement at different local densities that were consistent with the predicted effects of intraspecific competition. At higher densities, lionfish exhibited greater activity levels, time away from shelter, and more short-term movements between coral patch reefs and surrounding habitats. However, these changes with density were not consistent throughout the day, with the greatest differences in behavior occurring at dusk. Although prey density was associated with changes in some foraging behaviors by individual lionfish, overall it appears that lionfish density was more important in explaining activity patterns. These spatial and temporal changes in behavior may, in turn, change which prey individuals and species are most susceptible to lionfish predation.

Similar to prior studies in both their native and invaded ranges, I observed high levels of lionfish activity at dawn and dusk but very little activity

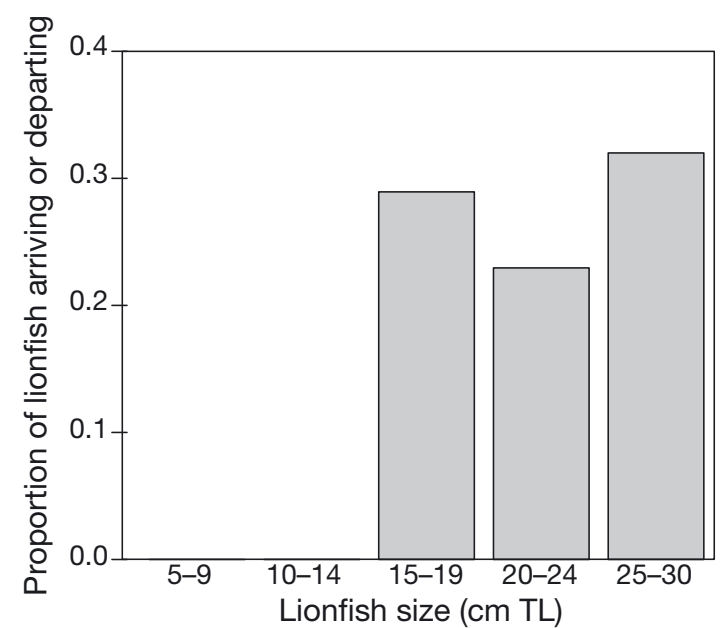

Fig. 4. Pterois volitans. Proportion of lionfish within each size class that arrived at, or departed from, the reefs. Sample sizes (number of lionfish) in each size class (from smallest to largest): 7, 10, 235, 61, and 25 during the middle of the day (Green et al. 2011, Cure et al. 2012, McTee \& Grubich 2014). Despite this overall consistency in diel activity patterns, there is still considerable variation in lionfish activity levels among locations within both their native and invaded ranges due in part to local differences in habitat, current strength, and prey availability (Cure et al. 2012). The differences in behavior on reefs with varying lionfish densities in the present study, combined with the wide range of lionfish population density both within and between oceans (Green \& Côté 2009, Darling et al. 2011, Kulbicki et al. 2012), suggest that local lionfish density may also help explain some of the site-specific variation in hunting behavior.

Exploitative competition for food is the likely cause of reduced growth rates in juvenile lionfish at higher densities (Benkwitt 2013, 2015). However, if exploitative competition for food was the main driver of changes in lionfish foraging behavior, then lionfish should exhibit greater hunting, activity, and movement at lower prey densities regardless of lionfish density, which was not the case in this study. Instead, individual lionfish spent more time hunting but less time active at higher prey densities, which suggests that they may spend less time searching for prey at higher prey densities (Anholt \& Werner 1995, Lubin \& Henschel 1996, Harding et al. 2007). In contrast, the proportion of lionfish on each reef that were hunting, active, sheltering, and moving did not vary with prey density. A possible explanation is that the species composition of prey has a larger influence on lionfish foraging behavior than total prey density. Lionfish exhibit diet preferences for certain prey characteristics, with small, solitary, bottom-dwelling fishes most susceptible to lionfish predation (Green \& Côté 2014). Therefore, teasing apart the influence of overall prey density compared with densities of preferred prey may further clarify the role of exploitative competition in affecting the foraging behavior of lionfish.

In contrast, many aspects of lionfish activity changed at increased lionfish densities, which suggests that interference competition is the main form of competition among lionfish and is driving the changes in lionfish foraging behavior. However, aggressive interactions between lionfish are rare (Cure et al. 2012), and I likewise observed few apparent aggressive encounters between lionfish at any density. Instead, lionfish may interfere with each other's foraging efficiency in ways other than direct aggression (Krause \& Ruxton 2002). For example, in several instances I observed one lionfish strike at a prey fish, and immediately thereafter several others swam to 
the same location. Even without being aggressive, the presence of these other lionfish could potentially decrease the foraging efficiency of some individuals. In addition, perceived competition, in the form of mirrors or competitors in separate tanks, causes changes in the foraging activity and behavior of many other species (Barnard et al. 1983, Dill \& Fraser 1984, Nonacs \& Calabi 1992), further suggesting that even without direct aggressive encounters, conspecifics could have a significant effect on lionfish foraging behavior.

Escaping intraspecific competition is a major driver of density-dependent movement in many coral-reef fishes (Abesamis \& Russ 2005, Grüss et al. 2011, Green et al. 2015), and a tagging study of lionfish conducted over the course of several months also found greater movement among patch reefs at higher lionfish densities (Tamburello \& Côté 2015). The crepuscular movements observed in the present study, however, appeared to be short-term foraging excursions given that approximately half of the lionfish returned to the same reef within the observation period, and lionfish in this system cause reductions in prey fish populations in the areas surrounding coral patch reefs up to at least $30 \mathrm{~m}$ from the nearest reef (Benkwitt 2016). Many other families of coral-reef fishes, including grunts (Haemulidae) and snapper (Lutjanidae), exhibit similar crepuscular movements between coral patch reefs and seagrass beds. These fishes leave their daytime reef shelters and forage in the surrounding seagrass at night, with important consequences for prey populations as well as community structure and nutrient transfer (Nagelkerken 2009, Ogden et al. 2014). Several species of scorpionfish (Scorpaenidae), which are in the same family as lionfish, also leave their shelter in the evening, forage at night, and return to the same shelter in the morning (Harmelin-Vivien \& Bouchon 1976).

The effects of intraspecific competition are often asymmetric, such that smaller, subordinate individuals in a population are most affected (Jones 1991, Peckarsky \& Cowan 1991, Davey et al. 2005, Nilsson 2006, Ward et al. 2006, Samhouri et al. 2009). If this is the case, then only certain individuals may change their foraging locations and behavior at higher levels of competition (Webster 2004, Breed et al. 2013). In the present study, the behaviors of randomly selected individual lionfish were fairly consistent with the initial behaviors of all lionfish on the reefs, which suggests that the effects of competition may be equally experienced by all individuals. However, no focal observations were conducted on lionfish less than $13 \mathrm{~cm} \mathrm{TL}$, so there may be differences in the behavior of the smallest individuals that were not captured in the present study. In terms of movement, larger lionfish were more likely to travel between patch reefs and the surrounding habitats, with smaller lionfish $(<15 \mathrm{~cm}$ TL) never departing from their home reefs. Similarly, previous studies of lionfish movement have found high site fidelity of small lionfish over the course of several months (Jud \& Layman 2012, Benkwitt 2013, Tamburello \& Côté 2015), although some larger lionfish also have high site fidelity (Akins et al. 2014). This apparent discrepancy may be caused by factors besides competition. Smaller individuals may remain closer to shelter as an adaptive response to predation (Lima \& Dill 1990), although there are few documented predators of lionfish in either their native or invaded range (Bernadsky \& Goulet 1991, Maljković et al. 2008). Smaller lionfish may also be more affected by strong ocean currents, and therefore remain sheltered on coral patch reefs because they are unable to swim into open areas. Finally, smaller lionfish consume different prey than larger lionfish, as there is an ontogenetic shift from a primarily invertebrate-based to a fish-based diet by the time lionfish reach approximately $20 \mathrm{~cm}$ TL (Morris \& Akins 2009, Muñoz et al. 2011). Consequently, smaller individuals may not need to forage over broader distances because their preferred food may not be depleted near reefs. This seems likely given that the majority of lionfish were between 15 and $25 \mathrm{~cm} \mathrm{TL}$, with only a few smaller individuals on each reef. Therefore, the majority of competition for food likely occurred between individuals in larger size classes.

Although intraspecific competition is a likely explanation for increased activity and movement of lionfish at higher densities, there are several other non-mutually exclusive possibilities. First, at higher densities there may be more opportunities to engage in group hunting behavior, which has been shown to increase per-capita consumption rates of lionfish in the Indo-Pacific (Kendall 1990, Lönnstedt et al. 2014). If invasive lionfish also have increased hunting success when in groups, then there may be an advantage to being more active and increasing their foraging movements at higher densities. Lionfish may also spend less time sheltering and undergo more foraging movements at higher densities due to differences in the perceived risk of being attacked by larger predators. Even when a prey species is not subject to direct predation, it may still modify its behavior in response to predators, so departing from the relatively safe shelter of the reefs in groups may provide 'safety in numbers' for lionfish (Creel \& 
Christianson 2008). Finally, some activity and movement into the surrounding seagrass may be related to spawning behavior, which likely occurs at night. On one occasion, I observed apparent courtship behavior similar to that described by Fishelson (1975) and Green et al. (2011). Three lionfish (between 19 and $28 \mathrm{~cm} \mathrm{TL}$ ) rapidly departed the reef, and once $20 \mathrm{~m}$ away in the open sand and seagrass they swam in circles around each other for approximately $2 \mathrm{~min}$. Two lionfish then returned to the reef while the remaining lionfish continued swimming rapidly away from the reef for at least $200 \mathrm{~m}$. The fact that lionfish can spawn up to every $4 \mathrm{~d}$ (Morris 2009) suggests another explanation for why larger lionfish departed the reefs on a regular basis, especially when there were higher local densities of mature adults.

Overall, the observed behavioral differences among invasive lionfish at different densities may have implications for native prey populations. There was a peak in feeding and activity at dawn regardless of lionfish density, but at dusk lionfish were more active only at higher densities. This observation suggests that native prey species that are primarily active at dusk will be affected only in areas with high lionfish densities. At both dawn and dusk, there was increased movement to and from habitats surrounding patch reefs at higher lionfish densities. Given that lionfish deplete prey populations in the habitats surrounding coral patch reefs (Benkwitt 2016), lionfish at higher densities may be causing greater reductions in a wider range of prey species, potentially including juveniles of commercially and ecologically important fishes that use seagrass beds as nursery grounds (Nagelkerken 2009, Ogden et al. 2014). In contrast, lionfish were almost always resting during the middle of the day regardless of lionfish density, which suggests that strictly diurnal fishes may be relatively safe from lionfish predation when these prey fishes are most active. In addition to increasing their time spent foraging and their foraging movements, many fishes shift to feeding on less preferred prey at higher densities (Coates 1980, Dill 1983, Holbrook \& Schmitt 1992, Schindler et al. 1997, Svanbäck \& Persson 2004, Agashe \& Bolnick 2010). There is currently no evidence that lionfish have different isotopic diet signatures at sites with high compared with low lionfish densities (J. Curtis unpubl. data), but if they do alter their diets at higher densities, then there may be even more consequences for prey populations.

Future studies should be conducted to determine the extent to which these results apply to other locations with different lionfish densities and habitat characteristics. Densities of lionfish observed here (mean $=3763$ lionfish per hectare) are comparable to the maximum reported densities from small artificial structures in the Gulf of Mexico (3850 lionfish per hectare; Dahl \& Patterson 2014), but higher than those observed on larger patch and continuous reefs in many parts of the invaded range (mean 3-640 lionfish per hectare; McTee \& Grubich 2014). Based on these differences, the effects of lionfish density on patch reefs where lionfish are concentrated within small, isolated areas may be diluted when scaled up to continuous reefs. However, even on larger reefs, lionfish often aggregate in small groups around structures during the day, and there is some evidence that on large patch reefs $\left(100-1200 \mathrm{~m}^{2}\right)$ lionfish similarly move over a broader area including the surrounding sand while foraging during crepuscular times (A. C. D. Davis unpubl. obs.).

The main method of managing lionfish populations is through manual removal by divers, which is a time- and labor-intensive process. However, removals can significantly reduce local lionfish abundances (Frazer et al. 2012, de León et al. 2013) and even partial removals can help maintain native prey populations on coral patch reefs (Green et al. 2014). Given that at higher densities lionfish also have increased activity levels at dusk and movements at both dawn and dusk, removals on patch reefs may be most efficient during midday when lionfish are aggregated on the reefs. Furthermore, removals may have more benefits than previously documented. By keeping lionfish densities low, managers may reduce the local foraging movements of lionfish and thus help maintain native fish communities in multiple habitats.

Acknowledgements. Funding was provided by National Science Foundation (NSF) grant OCE-12-33027 awarded to M. A. Hixon, and an NSF Graduate Research Fellowship, an American Society of Ichthyologists and Herpetologists Raney Fund Award, and Oregon State University travel grants awarded to the author. This manuscript is a chapter from the author's doctoral dissertation, and she thanks her committee: M. A. Hixon (advisor), S. A. Heppell, S. S. Heppell, L. Madsen, and B. A. Menge. Helpful comments on this study and earlier versions of the manuscript were also provided by E. Brush, A. C. D. Davis, E. Dilley, S. J. Green, K. I. Ingeman, T. L. Kindinger, P. J. Lyons, and L. J. Tuttle. The staff of The Cape Eleuthera Institute, K. I. Ingeman, T. L. Kindinger, and L. J. Tuttle provided field support, and M. Crell and S. Vojnovich assisted with data entry.

\section{LITERATURE CITED}

Abesamis RA, Russ GR (2005) Density-dependent spillover from a marine reserve: long-term evidence. Ecol Appl 15: 1798-1812 
Agashe D, Bolnick DI (2010) Intraspecific genetic variation and competition interact to influence niche expansion. Proc R Soc B 277:2915-2924

Akins JL, Morris JA, Green SJ (2014) In situ tagging technique for fishes provides insight into growth and movement of invasive lionfish. Ecol Evol 4:3768-3777

Albins MA (2013) Effects of invasive Pacific red lionfish Pterois volitans versus a native predator on Bahamian coral-reef fish communities. Biol Invasions 15:29-43

> Albins M (2015) Invasive Pacific lionfish Pterois volitans reduce abundance and species richness of native Bahamian coral-reef fishes. Mar Ecol Prog Ser 522: 231-243

Albins MA, Hixon MA (2008) Invasive Indo-Pacific lionfish Pterois volitans reduce recruitment of Atlantic coral-reef fishes. Mar Ecol Prog Ser 367:233-238

Albins MA, Hixon MA (2013) Worst case scenario: potential long-term effects of invasive predatory lionfish (Pterois volitans) on Atlantic and Caribbean coral-reef communities. Environ Biol Fishes 96:1151-1157

Anholt BR, Werner EE (1995) Interaction between food availability and predation mortality mediated by adaptive behavior. Ecology 76:2230-2234

Anton A, Simpson MS, Vu I (2014) Environmental and biotic correlates to lionfish invasion success in Bahamian coral reefs. PLOS One 9:e106229

Barnard CJ, Brown CAJ, Gray-Wallis J (1983) Time and energy budgets and competition in the common shrew (Sorex araneus L.). Behav Ecol Sociobiol 13:13-18

Bates D, Maechler M, Bolker B, Walker S (2014) lme4: linear mixed-effects models using Eigen and S4. R Package Version 11-7. https://cran.r-project.org/web/packages/ lme4

Benkwitt CE (2013) Density-dependent growth in invasive lionfish (Pterois volitans). PLOS One 8:e66995

> Benkwitt CE (2015) Non-linear effects of invasive lionfish density on native coral-reef fish communities. Biol Invasions 17:1383-1395

Benkwitt CE (2016) Central-place foraging and ecological effects of an invasive predator across multiple habitats. Ecology, doi:10.1002/ecy.1477

- Bernadsky G, Goulet D (1991) A natural predator of the lionfish, Pterois miles. Copeia 1991:230-231

Bohlin T, Johnsson JI (2004) A model on foraging activity and group size: can the relative importance of predation risk dilution and competition be evaluated experimentally? Anim Behav 68:F1-F5

> Bolker BM, Brooks ME, Clark CJ, Geange SW, Poulsen JR, Stevens MHH, White JSS (2009) Generalized linear mixed models: a practical guide for ecology and evolution. Trends Ecol Evol 24:127-135

Breed GA, Bowen WD, Leonard ML (2013) Behavioral signature of intraspecific competition and density dependence in colony-breeding marine predators. Ecol Evol 3: 3838-3854

Clark CW, Mangel M (1986) The evolutionary advantages of group foraging. Theor Popul Biol 30:45-75

> Clark ME, Wolcott TG, Wolcott DL, Hines AH (2000) Foraging behavior of an estuarine predator, the blue crab Callinectes sapidus in a patchy environment. Ecography 23:21-31

Coates D (1980) Prey-size intake in humbug damselfish, Dascyllus aruanus (Pisces, Pomacentridae) living within social groups. J Anim Ecol 49:335-340

Côté IM, Maljkovic A (2010) Predation rates of Indo-Pacific lionfish on Bahamian coral reefs. Mar Ecol Prog Ser 404: 219-225

> Côté IM, Green SJ, Hixon MA (2013) Predatory fish invaders: insights from Indo-Pacific lionfish in the western Atlantic and Caribbean. Biol Conserv 164:50-61

Côté IM, Darling ES, Malpica-Cruz L, Smith NS, Green SJ, Curtis-Quick J, Layman C (2014) What doesn't kill you makes you wary? Effect of repeated culling on the behaviour of an invasive predator. PLOS One 9:e94248

Courchamp F, Clutton-Brock T, Grenfell B (1999) Inverse density dependence and the Allee effect. Trends Ecol Evol 14:405-410

> Creel S, Christianson D (2008) Relationships between direct predation and risk effects. Trends Ecol Evol 23:194-201

> Cure K, Benkwitt CE, Kindinger TL, Pickering EA, Pusack TJ, McIlwain JL, Hixon MA (2012) Comparative behavior of red lionfish Pterois volitans on native Pacific versus invaded Atlantic coral reefs. Mar Ecol Prog Ser 467: 181-192

> Dahl KA, Patterson WF (2014) Habitat-specific density and diet of rapidly expanding invasive red lionfish, Pterois volitans, populations in the northern Gulf of Mexico. PLOS One 9:e105852

Darling ES, Green SJ, O'Leary JK, Côté IM (2011) IndoPacific lionfish are larger and more abundant on invaded reefs: a comparison of Kenyan and Bahamian lionfish populations. Biol Invasions 13:2045-2051

> Davey AJH, Hawkins SJ, Turner GF, Doncaster CP (2005) Size-dependent microhabitat use and intraspecific competition in Cottus gobio. J Fish Biol 67:428-443

de León R, Vane K, Bertuol P, Chamberland VC, Simal F, Imms E, Vermeij MJA (2013) Effectiveness of lionfish removal efforts in the southern Caribbean. Endang Species Res 22:175-182

> Dill LM (1983) Adaptive flexibility in the foraging behavior of fishes. Can J Fish Aquat Sci 40:398-408

> Dill LM, Fraser AHG (1984) Risk of predation and the feeding behavior of juvenile coho salmon (Oncorhynchus kisutch). Behav Ecol Sociobiol 16:65-71

Fishelson L (1975) Ethology and reproduction of pteroid fishes found in the Gulf of Aqaba (Red Sea), especially Dendrochirus brachypterus (Cuvier), (Pteroidae, Teleostei). PSZN Mar Ecol 39:635-656

Forrester GE (2015) Competition in reef fishes. In: Mora C (ed) Ecology of fishes on coral reefs. Cambridge University Press, Cambridge, p 34-40

> Forrester GE, Evans B, Steele MA, Vance RR (2006) Assessing the magnitude of intra- and interspecific competition in two coral reef fishes. Oecologia 148:632-640

> Frazer TK, Jacoby CA, Edwards MA, Barry SC, Manfrino CM (2012) Coping with the lionfish invasion: Can targeted removals yield beneficial effects? Rev Fish Sci 20: 185-191

Gascoigne JC, Lipcius RN (2004) Allee effects driven by predation. J Appl Ecol 41:801-810

> Grand TC, Dill LM (1999) The effect of group size on the foraging behaviour of juvenile coho salmon: reduction of predation risk or increased competition? Anim Behav 58: 443-451

> Green SJ, Côté IM (2009) Record densities of Indo-Pacific lionfish on Bahamian coral reefs. Coral Reefs 28:107

Green SJ, Côté IM (2014) Trait-based diet selection: prey behaviour and morphology predict vulnerability to predation in reef fish communities. J Anim Ecol 83: 1451-1460 
Green SJ, Akins JL, Côté IM (2011) Foraging behaviour and prey consumption in the Indo-Pacific lionfish on Bahamian coral reefs. Mar Ecol Prog Ser 433:159-167

Green SJ, Dulvy NK, Brooks AML, Akins JL, Cooper AB, Miller S, Côté IM (2014) Linking removal targets to the ecological effects of invaders: a predictive model and field test. Ecol Appl 24:1311-1322

> Green AL, Maypa AP, Almany GR, Rhodes KL and others (2015) Larval dispersal and movement patterns of coral reef fishes, and implications for marine reserve network design. Biol Rev Camb Philos Soc 90:1215-1247

> Grosholz ED, Ruiz GM (2003) Biological invasions drive size increases in marine and estuarine invertebrates. Ecol Lett 6:700-705

> Grüss A, Kaplan DM, Guénette S, Roberts CM, Botsford LW (2011) Consequences of adult and juvenile movement for marine protected areas. Biol Conserv 144:692-702

> Hackerott S, Valdivia A, Green SJ, Côté IM and others (2013) Native predators do not influence invasion success of Pacific lionfish on Caribbean reefs. PLOS One 8: e68259

> Harding AMA, Piatt JF, Schmutz JA, Shultz MT, Pelt TIV, Kettle AB, Speckman SG (2007) Prey density and the behavioral flexibility of a marine predator: the common murre (Uria aalge). Ecology 88:2024-2033

Harmelin-Vivien ML, Bouchon C (1976) Feeding behavior of some carnivorous fishes (Serranidae and Scorpaenidae) from Tulear (Madagascar). Mar Biol 37:329-340

Hixon MA, Pacala SW, Sandin SA (2002) Population regulation: historical context and contemporary challenges of open vs. closed systems. Ecology 83:1490-1508

> Holbrook SJ, Schmitt RJ (1992) Causes and consequences of dietary specialization in surfperches: patch choice and intraspecific competition. Ecology 73:402-412

Jones GP (1991) Postrecruitment processes in the ecology of coral reef fish populations: a multifactorial perspective. In: Sale PF (ed) The ecology of fishes on coral reefs. Academic Press, San Diego, CA, p 294-328

Jud ZR, Layman CA (2012) Site fidelity and movement patterns of invasive lionfish, Pterois spp., in a Florida estuary. J Exp Mar Biol Ecol 414-415:69-74

Kaspersson R, Hojesjo J, Pedersen S (2010) Effects of density on foraging success and aggression in age-structured groups of brown trout. Anim Behav 79:709-715

Keddy PA (2001) Competition, 2nd edn. Kluwer Academic Publishers, Dordecht

Kendall JJ (1990) Further evidence of cooperative foraging by the turkeyfish Pterois miles in the Gulf of Aqaba, Red Sea, with comments on safety and first aid. Proc Am Acad Underw Sci Diving Symp 10:209-223

Krause DJ, Ruxton GD (2002) Living in groups. Oxford University Press, New York, NY

Kronfeld-Schor N, Dayan T (2003) Partitioning of time as an ecological resource. Annu Rev Ecol Evol Syst 34: 153-181

Kulbicki M, Beets J, Chabanet P, Cure K and others (2012) Distributions of Indo-Pacific lionfishes Pterois spp. in their native ranges: implications for the Atlantic invasion. Mar Ecol Prog Ser 446:189-205

> Lawton P (1987) Diel activity and foraging behavior of juvenile American lobsters, Homarus americanus. Can J Fish Aquat Sci 44:1195-1205

Lima SL, Dill LM (1990) Behavioral decisions made under the risk of predation: a review and prospectus. Can J Zool 68:619-640
Lönnstedt OM, Ferrari MCO, Chivers DP (2014) Lionfish predators use flared fin displays to initiate cooperative hunting. Biol Lett 10:20140281

Lubin Y, Henschel J (1996) The influence of food supply on foraging behaviour in a desert spider. Oecologia 105: 64-73

> Mack RN, Simberloff D, Lonsdale MW, Evans H, Clout M, Bazzaz FA (2000) Biotic invasions: causes, epidemiology, global consequences, and control. Ecol Appl 10:689-710

Maljković A, Leeuwen TE, Cove SN (2008) Predation on the invasive red lionfish, Pterois volitans (Pisces: Scorpaenidae), by native groupers in the Bahamas. Coral Reefs 27:501

> McTee SA, Grubich JR (2014) Native densities, distribution, and diurnal activity of Red Sea lionfishes (Scorpaenidae). Mar Ecol Prog Ser 508:223-232

> Micheli F (1997) Effects of predator foraging behavior on patterns of prey mortality in marine soft bottoms. Ecol Monogr 67:203-224

> Mooney HA, Cleland EE (2001) The evolutionary impact of invasive species. Proc Natl Acad Sci USA 98: 5446-5451

Morris JA (2009) The biology and ecology of the invasive Indo-Pacific lionfish. PhD dissertation, North Carolina State University, Raleigh, NC

Morris JA, Akins JL (2009) Feeding ecology of invasive lionfish (Pterois volitans) in the Bahamian archipelago. Environ Biol Fishes 86:389-398

Mumby PJ, Harborne AR, Brumbaugh DR (2011) Grouper as a natural biocontrol of invasive lionfish. PLOS One 6:e21510

Muñoz RC, Currin CA, Whitfield PE (2011) Diet of invasive lionfish on hard bottom reefs of the Southeast USA: insights from stomach contents and stable isotopes. Mar Ecol Prog Ser 432:181-193

Murdoch WW (1994) Population regulation in theory and practice. Ecology 75:271-287

Nagelkerken I (2009) Ecological connectivity among tropical coastal ecosystems. Springer, Dordecht

Nilsson PA (2006) Avoid your neighbours: size-determined spatial distribution patterns among northern pike individuals. Oikos 113:251-258

Nonacs P, Calabi P (1992) Competition and predation risk: their perception alone affects ant colony growth. Proc R Soc B 249:95-99

Ogden JC, Nagelkerken I, McIvor CC (2014) Connectivity in the tropical coastal seascape. In: Bortone SA (ed) Interrelationships between corals and fisheries. CRC Press, Boca Raton, FL, p 253-274

> Packer C, Ruttan L (1988) The evolution of cooperative hunting. Am Nat 132:159-198

> Paddack MJ, Reynolds JD, Aguilar C, Appeldoorn RS and others (2009) Recent region-wide declines in Caribbean reef fish abundance. Curr Biol 19:590-595

> Parker IM, Simberloff D, Lonsdale WM, Goodell K and others (1999) Impact: toward a framework for understanding the ecological effects of invaders. Biol Invasions $1: 3-19$

Peckarsky BL, Cowan CA (1991) Consequences of larval intraspecific competition to stonefly growth and fecundity. Oecologia 88:277-288

Pintor LM, Sih A, Kerby JL (2009) Behavioral correlations provide a mechanism for explaining high invader densities and increased impacts on native prey. Ecology 90: $581-587$ 
R Core Team (2013) R: a language and environment for statistical computing. R foundation for statistical computing, Vienna

Ruttenberg BI, Schofield PJ, Akins JL, Acosta A and others (2012) Rapid invasion of Indo-Pacific lionfishes (Pterois volitans and Pterois miles) in the Florida Keys, USA: evidence from multiple pre- and post-invasion data sets. Bull Mar Sci 88:1051-1059

Sakai AK, Allendorf FW, Holt JS, Lodge DM and others (2001) The population biology of invasive species. Annu Rev Ecol Syst 32:305-332

Salo P, Korpimaki E, Banks PB, Nordstrom M, Dickman CR (2007) Alien predators are more dangerous than native predators to prey populations. Proc R Soc B 274: 1237-1243

Samhouri JF, Steele MA, Forrester GE (2009) Inter-cohort competition drives density dependence and selective mortality in a marine fish. Ecology 90:1009-1020

Schindler DE, Hodgson JR, Kitchell JF (1997) Densitydependent changes in individual foraging specialization of largemouth bass. Oecologia 110:592-600

Schofield PJ (2010) Update on geographic spread of invasive lionfishes (Pterois volitans [Linnaeus, 1758] and P. miles [Bennett, 1828]) in the Western North Atlantic Ocean, Caribbean Sea and Gulf of Mexico. Aquat Invasions 5: S117-S122

Shaw JJ, Tregenza T, Parker GA, Harvey IF (1995) Evolutionarily stable foraging speeds in feeding scrambles: a model and an experimental test. Proc R Soc B 260: 273-277

Editorial responsibility: Charles Birkeland, Honolulu, Hawaii, USA
Stallings CD (2009) Fishery-independent data reveal negative effect of human population density on Caribbean predatory fish communities. PLOS One 4:e5333

Svanbäck R, Persson L (2004) Individual diet specialization, niche width and population dynamics: implications for trophic polymorphisms. J Anim Ecol 73:973-982

Tamburello N, Côté IM (2015) Movement ecology of Indo-Pacific lionfish on Caribbean coral reefs and its implications for invasion dynamics. Biol Invasions 17:1639-1653

Valdivia A, Bruno JF, Cox CE, Hackerott S, Green SJ (2014) Re-examining the relationship between invasive lionfish and native grouper in the Caribbean. PeerJ 2:e348

Ward AJW, Webster MM, Hart PJB (2006) Intraspecific food competition in fishes. Fish Fish 7:231-261

- Wasserberg GP, Kotler B, Abramsky Z (2006) The role of site, habitat, seasonality and competition in determining the nightly activity patterns of psammophilic gerbils in a centrifugally organized community. Oikos 112:573-579

Webster MS (2004) Density dependence via intercohort competition in a coral-reef fish. Ecology 85:986-994

White JW, Warner RR (2007) Behavioral and energetic costs of group membership in a coral reef fish. Oecologia 154: 423-433

Whitfield PE, Hare JA, David AW, Harter SL, Muñoz RC, Addison CM (2007) Abundance estimates of the IndoPacific lionfish Pterois volitans/miles complex in the Western North Atlantic. Biol Invasions 9:53-64

Zuur AF, Ieno EN, Walker NJ, Saveliev AA, Smith GM (2009) Mixed effects models and extensions in ecology with R. Springer, New York, NY

Submitted: January 19, 2016; Accepted: May 9, 2016

Proofs received from author(s): July 2, 2016 